\title{
Participação e colegialidade na política democrática: o caso do Instituto de Aplicação Fernando Rodrigues da Silveira (CAp/UERJ)
}

Participation and collegiality in democratic politics: the case of Instituto de Educação Fernando Rodrigues da Silveira (CAp/UERJ)

\section{Participación y colegialidad en política democrática:}

el caso del Instituto de Aplicação Fernando Rodrigues da Silveira (CAp/UERJ)

MARCELA MORAES CASTRO*

Universidade Federal do Rio de Janeiro, Rio de Janeiro-RJ, Brasil.

BETHANIA BITTENCOURT ${ }^{* *}$

Universidade Federal do Rio de Janeiro, Rio de Janeiro-RJ, Brasil.

CAROLINE DOMINGUES DA SILVA TELES ASSIS

Universidade Federal do Rio de Janeiro, Rio de Janeiro-RJ, Brasil.

JANAINA MOREIRA DE OLIVEIRA GOULART

Universidade Federal do Rio de Janeiro, Rio de Janeiro-RJ, Brasil.

\begin{abstract}
RESUMO: Discute-se a participação como condição da democracia da Associação de Pais e Professores (APP) pertencente ao Instituto de Aplicação Fernando Rodrigues da Silveira, colégio estadual da Universidade Estadual do Rio de Janeiro, no contexto da não oferta
\end{abstract}

\footnotetext{
* Mestre e Doutoranda em Educação pela Universidade Federal do Rio de Janeiro. Atua como Técnica em Assuntos Educacionais da Universidade Federal do Rio de Janeiro. E-mail: <marcelamoraesdecastro@gmail.com>.

** Mestre e Doutoranda em Educação pela Universidade Federal do Rio de Janeiro. Atua como Orientadora Pedagógica na Rede Municipal de Educação de Queimados-RJ e como Professora da Educação Básica da Rede Municipal de Educação de Mesquita-RJ. E-mail: <bethania.ufrj@gmail.com>.

*** Mestranda em Educação pela Universidade Federal do Rio de Janeiro. Graduada em Letras Português/ Inglês pela mesma instituição. É Professora da Educação Básica da Rede Municipal do Rio de Janeiro-RJ. E-mail:<caroline.domingues@yahoo.com>.

**** Mestre em Educação pela Universidade Federal de Juiz de Fora e Doutoranda em Educação pela Universidade Federal do Rio de Janeiro. Atua como Professora da Educação Básica e como Professora Inspetora Escolar da Rede Estadual do Rio de Janeiro-RJ. E-mail: <janaigtmetro5@gmail.com>.
} 
de alimentação escolar, instituída a obrigatoriedade pela Lei $\mathrm{n}^{\circ}$ 11.947/2009. São analisados pontos de tensão produzidos pela situação em mensagens eletrônicas do grupo da APP. O ciclo de políticas permite entender a articulação da demanda para legitimá-la no Legislativo. Conclui-se que o cenário político indica a oferta de merenda fria sem garantir a Lei.

Palavras-chave: Políticas públicas educacionais. Gestão democrática. Participação. Colegialidade. Alimentação escolar.

ABSTRACT : Participation as a condition of democracy of the Parent Teacher Association (PTA/APP) belonging to the Instituto de Educação Fernando Rodrigues da Silveira state school of the State University of Rio de Janeiro, in the context of the non-provision of school meals, is discussed as its obligation by Law No. 11.947 / 2009. Stress points produced by the situation are analyzed in electronic messages from the APP group. The policy cycle allows us to understand the articulation of demand to legitimize it in the Legislature. It is concluded that the political scenario indicates the offer of cold meals without guaranteeing the law.

Keywords: Educational public policies. Democratic management. Participation. Collegiality. School feeding.

RESUMEN: Se discute la participación como condición de la democracia de la Asociación de Padres y Maestros (APP) del Instituto de Aplicação Fernando Rodrigues da Silveira, escuela secundaria de la Universidade Estadual do Rio de Janeiro, en el contexto de la no provisión de alimentación escolar, cuya obligatoriedad fue instituida por la Ley $N^{\circ}$ 11.947/2009. Los puntos de tensión producidos por la situación se analizan en mensajes electrónicos del grupo de la APP. El ciclo de políticas nos permite comprender la articulación de la demanda para legitimarla en el Legislativo. Se concluye que el escenario político indica la oferta de merienda fría, sin garantizar la Ley.

Palabras clave: Políticas públicas educacionales. Gestión democrática. Participación. Colegialidad. Alimentación escolar. 


\section{Introdução}

s questões que trazemos para o debate estão relacionadas à ausência de oferta de alimentação escolar no Instituto de Aplicação Fernando Rodrigues da Sil1 veira (CAp), contrariando a Lei Federal nº 11.947/2009 do Programa Nacional de Alimentação Escolar (Pnae), que afirma no art. 3a a "alimentação escolar como direito dos alunos da educação básica pública" sendo considerada como "dever do Estado promovida e incentivada com vistas ao atendimento das diretrizes estabelecidas nesta Lei". Assim, no contexto desta lei e a partir da não oferta de alimentação, interessa-nos analisar o movimento dos sujeitos que compõem o colegiado da Associação de Pais e Professores (APP), no que se refere à participação deste grupo na articulação pela demanda para o cumprimento do direito, analisando pontos de tensão produzidos pela ausência deste na instituição específica.

O CAp é uma escola pública estadual vinculada à Universidade do Estado do Rio de Janeiro (Uerj), criada a partir do Decreto-lei nº 9.053/1946 e inaugurada em $1^{\circ}$ de Abril de 1957. Atualmente, localiza-se no bairro do Rio Comprido, Zona Norte da cidade do Rio de Janeiro, funcionando de forma provisória de acordo com o Projeto Político Pedagógico do CAp (2013). A escola tem por objetivo ofertar a educação básica, bem como a formação de professores, graduandos da Uerj. A educação básica do CAp atendia, em 2018, a 891 alunos (FUNDAÇÃO LEMANN, 2019) nas etapas do ensino fundamental e médio, e, por ser integrado à universidade, as atividades de ensino, pesquisa, e extensão se articulam à sua proposta pedagógica.

Para análise, consideramos o contexto a Lei ${ }^{\circ} 11.947 / 2009$ do Pnae, que trata da oferta de alimentação escolar para as escolas da rede pública; o questionário do Censo Escolar 2018, que institucionaliza a situação da oferta de alimentação escolar; bem como, o relato pelos representantes da APP da ata da Audiência Pública da Comissão de Educação, realizada em 20 de março de 2019 no Palácio Tiradentes no RJ, na qual o Legislativo adensa a demanda sobre a necessidade de atendimento da oferta em questão.

Desse modo, a partir da pauta pela alimentação escolar indagamos: como a Associação de Pais, a qual entendemos como membros da comunidade escolar, reabre a demanda sobre a não oferta de alimentação e a encaminha para o Poder Legislativo? A comunidade escolar pode ser considerada como peça importante para a solução de problemas da escola? Ela se constitui como parte integrante da (re)construção de políticas públicas educacionais?

Após esta introdução, dividimos o artigo em mais três seções, além das considerações finais deste artigo. Na segunda, discutimos democracia e participação, considerando que a ação política democrática inexiste sem a participação dos sujeitos nos espaços institucionalizados da política. Em seguida, colocamos em relevo a participação como ação política do grupo colegiado da APP. Na terceira seção, assumindo como contexto a Lei do Pnae, analisamos as conversas do grupo de responsáveis da APP no encaminhamento 
da demanda pela alimentação escolar para o Legislativo. Por fim, tecemos considerações que nos permitirão dar continuidade à reflexão sobre participação e colegialidade como elemento constituinte da gestão democrática na escola.

\section{Democracia e participação: uma interlocução com a escola pública}

Nosso debate sobre gestão democrática na escola considera, sobretudo, as discussões que assumem a participação como mecanismo da democracia. Neste sentido, para dialogarmos com a escola, partimos da proposta de Lima (1998), entendendo que a colegialidade pressupõe a participação e esta se sedimenta através de diversos coletivos existentes na escola. Para o autor, a colegialidade mobiliza a ideia de sujeitos com lugar de pertencimento, direito e dever de mobilização e ação política, ou seja, participação. A APP , no CAp, constitui-se como um espaço institucionalizado de participação com reuniões regulares na escola - uma por trimestre - e através do grupo de WhatsApp.

Sobre a construção de políticas públicas educacionais, as entendemos como processos complexos nos quais circulam diversos sujeitos em contextos distintos na disputa por determinados fins. Igualmente, na análise que propomos, consideramos a disputa entre os contextos de influência e da prática; no primeiro, estão situados os sujeitos do Legislativo que pensam/desenham como ideal a política para a escola, afirmando a alimentação escolar como direito dos alunos da rede pública de educação. Já o contexto da prática, neste texto, mantém relação com os responsáveis pelos estudantes do CAp vinculados à APP, os quais fazem ressoar a não oferta pela alimentação escolar. Neste grupo, estão articulados os responsáveis, membros da comunidade escolar e também destinatários da política, na perspectiva de mobilização de uma ação política pela oferta de alimentação escolar para os estudantes do CAp.

Assumimos que os movimentos políticos constituem uma agenda envolvendo grupos de interesse distintos que atuam nos diversos contextos da política com embates para objetivar o projeto no qual acreditam (BOWE; BALL; GOLD, 1992). Nesta aposta, admite-se a possibilidade de articulação entre os contextos, potencializando a ação política dos grupos que estão fora do contexto do Estado, mas nele interferem. Isto posto, consideramos o poder do Estado enquanto instituição constituída por sujeitos, mas supomos que quando um contexto consegue articular suas demandas a outro contexto, os dois juntos assumem maior força para aquele determinado fim. Isso implica em dizer que não há um consenso único dentro dos contextos, pois as disputas internas movimentam os sujeitos para buscar as articulações pelo que apostam, e, dessa maneira, o empoderamento de uma demanda pode vir a acontecer. Acreditamos que alguns dos sujeitos do contexto da prática, em diálogo a outros sujeitos do contexto de influência, podem fazer valer a demanda pela alimentação escolar não ofertada no CAp. 
Para Mouffe (2010), a inscrição de uma cultura democrática mobiliza "algo do poder do povo" e, sobre esta, precisa ser indagado o que uma determinada sociedade tem a dizer a respeito deste poder, e de que forma esta sociedade institucionaliza a participação da comunidade em decisões interpeladas por este poder. Para a autora, a participação no campo mais amplo da sociedade está prevista em processos políticos, portanto, o caminho de uma análise de políticas nos faz ponderar sobre a possibilidade das formas de manifestações dos diversos grupos sociais nas decisões que dizem respeito ao seu cotidiano.

No que se refere à gestão democrática e analisando especificamente a participação deste grupo na escola, Peroni (2012) afirma que

a participação em conselhos e a eleição para diretores são processos de aprendizagem da democracia, tanto para a comunidade escolar, quanto para a comunidade em geral, porque a participação, após um largo período de ditadura, não se apresenta consolidada (PERONI, 2012:26).

Ao partirmos dessas concepções, consideramos a participação da comunidade na escola um importante passo para a assunção de uma perspectiva democrática de gestão, na medida em que seu mecanismo está vinculado ao processo mais amplo de uma ordem democrática. Por isso, propomos analisar a ação política da APP do CAp, no intuito de compreender de que modo estes sujeitos se articulam na tentativa de solucionar a não oferta de alimentação pela escola. Nesse caso, definimos quem estamos considerando como sujeitos de direito à participação na escola.

Paro (2007, p.21) sugere uma definição de comunidade para pensar nos sujeitos com direito à participação na escola. Para o autor, a comunidade escolar se define pelo "conjunto de pais/famílias que, ou por residirem no âmbito regional servido por determinada escola, ou por terem fácil acesso físico a ela, são usuários, efetivos ou potenciais, de seus serviços". O exemplo do CAp nos exige um esforço para ampliar este conceito devido ao fato desta instituição não se configurar como uma escola de bairro, ou seja, que atenda, prioritariamente, aos moradores de uma determinada região, já que nela circulam alunos de diferentes bairros do RJ e até mesmo de municípios próximos.

Como parte da comunidade escolar do CAp consideramos o conjunto de responsáveis que se articulam, em alguma medida, em torno da aposta política por uma escola pública de qualidade, laica e socialmente referenciada, como afirma a Lei de Diretrizes e Bases da Educação Nacional (BRASIL, 1996). A esta comunidade estão associadas ações relativas aos mecanismos coletivos de participação e dentre estes colegiados estão os conselhos escolares, as associações de pais, mestres e funcionários não docentes, os grêmios estudantis e os conselhos de classe.

Logo, aprofundamos na próxima seção o debate sobre a participação na escola através do grupo de responsáveis pela APP e mantemos a nossa indagação: como pode a 
comunidade, por meio da ação política e assentada sobre o princípio da participação, movimentar o (re)desenho de políticas públicas para a escola no legislativo?

\section{A escola como campo institucional de demanda política}

Em 2016, no contexto do movimento de ocupação ${ }^{1}$ das escolas do RJ, a precariedade das instalações do Instituto e a não oferta de alimentação escolar se constituíram como pautas da agenda de mobilização dos estudantes, conforme divulgado pela mídia $(\mathrm{O}$ DIA, 2016), abrindo o problema para a sociedade. Na ocasião, deputados da Assembléia Legislativa do Estado do Rio de Janeiro (Alerj) estiveram no CAp para uma audiência pública com os alunos e levantaram a possibilidade de a Alerj, com recursos próprios, construir um "bandejão na escola", como é popularmente conhecido o restaurante universitário (COSTA, 2016). Ainda sem oferta de merenda no ano de 2019, um grupo de responsáveis pelos alunos da APP do CAp reassumiu a demanda pela merenda, pauta constante no movimento de ocupação dos estudantes em 2016, e que vinha sendo internamente tratada desde 2015, segundo depoimento de uma ex-integrante da APP.

Assim, problematizamos o contexto da não oferta de alimentação escolar a partir da reivindicação mínima pelo direito para o CAp em 2019, utilizando a demanda encaminhada pela APP ao Poder Legislativo do estado do RJ, com base em debates e relatos ocorridos no grupo de discussão em um aplicativo de mensagens (Whatsapp) deste grupo vinculado à APP. O grupo virtual, denominado Representantes da APP, foi criado em 2019 e possui, atualmente, 43 membros e 7 administradores integrantes da chapa que dirige a APP. Os membros são afiliados à Associação, um dos colegiados do CAp, e "visa o debate e busca de soluções na luta pelo CAp público, gratuito e de qualidade socialmente referenciada [...]" na "[...] luta pelo refeitório, merenda escolar já, prédio com infraestrutura adequada, acessibilidade e destravamento dos concursos públicos" (GRUPO APP, 2019). Para além do espaço institucional onde o grupo se reúne, esta forma de comunicação foi escolhida pelos responsáveis integrantes da APP por oportunizar aos membros um espaço para uma interação dinâmica e, por muitas vezes, em tempo real.

A colegialidade, como mecanismo de participação na escola pública democrática, associada à perspectiva de Lima (2014), compreende a gestão democrática a partir do tripé: participação, colegialidade e eleição. Desse modo, interessa-nos o diálogo que articula colegialidade e participação por considerarmos que a demanda pela oferta de alimentação é construída como uma ação política através do direito à participação. Uma participação institucionalizada que adensa à escola os sujeitos que constituem o grupo da APP do CAp.

Consideramos que, no regime democrático, a pluralidade de lutas identifica os sujeitos enquanto coletivos quando estas lutas conseguem se articular em torno de uma 
reivindicação num espaço institucional. Por outro lado, estes coletivos caracterizam-se também como o espaço da contradição, do pensamento divergente, uma dimensão que lhes é própria. Neste caminho, consideramos, como aponta Martins et al (2018), que grupos de interesse podem prevalecer nos diversos contextos e, no lugar da participação com poder decisório, práticas participacionistas podem vir a ocupar o cenário. Esse embate emerge por conta das características presentes no regime democrático, de acordo com a cena política, caracterizado pelas relações controversas de poder e pautado pela possibilidade de um grupo compor um melhor arranjo capaz de instituir certas ordens.

Entretanto, para Lima (2014), os órgãos compostos por representantes eleitos dos docentes, alunos e funcionários não-docentes podem constituir uma alternativa democrática de grande alcance, mais ainda, quando a participação nos processos de decisão ocorre na escola. A identificação de problemas, o diálogo, a contestação, a argumentação, a busca de soluções e as tomadas de decisão por parte dos membros dos colegiados, representando os coletivos da escola realizados através de reuniões e assembleias, indicam o alcance democrático destes grupos, como no caso da APP do CAp. Concordamos com Goulart e Amaral (2019) quando afirmam que "as assimetrias relacionais da/na escola não existem para serem vencidas a partir das leis [...], mas a partir de reflexões que emergem coletivamente sobre os resultados que as escolas e as suas respectivas comunidades estão colhendo". Nesta lógica é que a existência deste colegiado assume relevância no debate aqui proposto.

Sobre a possibilidade de ampliar o alcance da democracia na escola, Oliveira e Menezes (2018) defendem a importância da comunidade nos órgãos, pois ao mesmo tempo estes "contribuem para que os sujeitos aprendam a assumir responsabilidades" (MENEZES, 2018, p.892). Uma relação de ensino e aprendizagem, tanto para a instituição, quanto para a comunidade que nela circula, num processo voltado para a ação política, na construção de demandas cotidianas relativas ao contexto próprio de atuação. Nosso entendimento é que estes são elementos relevantes para a legitimação da democracia na escola e no encaminhamento de relações mais horizontais das decisões, na perspectiva de ampliar o espectro de alcance da gestão democrática.

Ainda referente à participação articulada à colegialidade, Lima (2014, p.1.072) reafirma a sua centralidade, pois, para o autor, a gestão democrática esvaziada de participação não tem coerência, uma vez que "somente o poder de decidir confere pleno sentido às práticas de governo democrático das escolas, rompendo com encenações participativas, com rituais, processos e métodos formalmente democráticos, mas a que falta substantividade democrática". A participação entendida por este viés exige mais do que o acesso à informaceão e o direito a ser informado, ou mesmo a publicidade dos atos, as propostas e sugestões, as auscultações e outros processos eventualmente despojados de poder de decisão (LIMA, 2014). Para o autor, ações periféricas não legitimam uma cultura democrática na escola. 
Presumimos, então, que os sujeitos que atuam no contexto da prática (BOWE; BALL; GOLD, 1992) - os responsáveis pelos alunos da APP - podem impulsionar mudanças no debate político. Por esta razão, consideramos que estes sujeitos integrantes da comunidade escolar são, também, produtores de políticas públicas e, por esta razão, torna-se caminho incontornável acompanhar as ações que movimentam a política na busca pela legitimação dos espaços de participação da comunidade que irão compor um desenho mais democrático de gestão.

Por este viés, é possível assumir que a escola pública é um espaço em que aqueles que por ela circulam se constituem como destinatários de políticas, e portanto, são sujeitos que precisam ter garantidos os espaços de participação na possibilidade de poder decidir sobre seu próprio governo e ser informado sobre as ações da escola.

\section{O direito à alimentação escolar: análise do plano da ação política}

Silva et al. (2018) destacam que o termo "alimentação escolar" tem sido utilizado para denominar o conjunto de refeições ofertadas pelo Pnae, decorrente de programas suplementares propostos pela LDB (BRASIL, 1996). Segundo Vinha (2016, p. 558), o Pnae visa a inclusão do direito à alimentacão na Constituição Federal como direito fundamental, no Art. 6º através da Emenda Constitucional nº 64, de 2010, como uma obrigação do Estado. Ainda conforme a autora, é a partir do ano 2000 que "a alimentação escolar passou a ser entendida como política de atendimento ao direito do aluno receber o alimento durante sua permanência na escola, em face de seu metabolismo e características fisiológicas" (2016, p.559), constituindo-se como uma importante política no Brasil (VINHA, 2016).

Ademais, a autora discorre sobre o período em que as políticas de alimentação e nutrição tinham como objetivo a redução da desnutrição como uma ação assistencial específica para grupos vulneráveis socialmente. Entretanto, a instituição da alimentação escolar como um direito de todos os alunos da rede pública de ensino emergiu como uma nova ideia ligada à estratégia de segurança alimentar e nutricional que tem seus fundamentos no Direito Humano à Alimentação Adequada e Saudável. Diante das questões postas acerca do não asseguramento da alimentação escolar no CAp, e em conformidade com o Pnae, chama-nos atenção a resposta do Censo Escolar 2018 (FUNDAÇÃO LEMANN, 2019) sobre a questão que indaga acerca da oferta, pois neste documento consta a declaração afirmativa da escola sobre o fornecimento de alimentação para os alunos.

Sobre este fato, é possível observar uma contradição entre o plano da orientação e o plano da ação. O primeiro, como destacado por Lima (2003), se constitui pelos textos políticos pensados e elaborados para serem realizados nas instituições e ações a ela destinadas, enquanto que o segundo traduz aquilo que acontece no cotidiano escolar, ou seja, o que ocorre no plano da ação. Observamos grave divergência nesta informação 
evidenciada pela gestão da escola, na medida em que a declaração da oferta de alimentação produz um apagamento da sua não oferta, uma omissão da gestão escolar para um problema que vem se estendendo, pelo menos, desde 2015, como conseguimos localizar através dos registros no grupo de Whatsapp.

É possível considerar com esta resposta ao questionário que a gestão da escola acaba por vendar os olhos do Executivo, bem como os do Legislativo, sobre a questão, interditando, de algum modo, uma solução para o problema, já que o registro de uma resposta em um documento legal é a referência para a ação do Executivo e do Legislativo. Desse modo, voltando o nosso olhar para as contradições do contexto da prática e fazendo uma relação com o plano da orientação para a ação, pautado pela Lei nº 11.947/2009 e o plano da ação organizacional, chamamos atenção para uma fala de um integrante da APP que aponta a lacuna existente entre estes.

Pelo que li sobre a merenda escolar nos ordenamentos da Seeduc, o CAp teria direito, pois ele é uma escola do estado, embora esteja vinculado à ciência e tecnologia (responsável representante- GRUPO APP, 2019).

Esta fala representa a possibilidade de justificar a demanda requerida pois, se no plano da orientação há uma inscrição através de um ordenamento legal, e no plano da prática não há a ação correlata, os responsáveis associados à APP encontram a grieta (MOUFFE; ERREJÓN, 2016) para questionar e recorrer ao Poder Legislativo do RJ. Apesar de não mencionar a Lei que trata do tema, o responsável expressa seu conhecimento a respeito da obrigação da oferta de alimentação escolar e se propõe a procurar pelos textos oficiais para que a base de seu requerimento esteja dentro da legalidade.

A necessidade de encontrar um espaço por onde as vozes dos destinatários da política pudessem ser ouvidas a fim de pleitear a garantia do direito da alimentação escolar conforme prevista em lei movimenta o grupo, constituindo uma agenda com vistas a colocá-la na pauta de ação do Poder Legislativo. Nessa perspectiva, através de uma conversa de um ex-representante da APP, um histórico de ações sobre a demanda pela alimentação escolar pôde ser resgatado:

O CAp-Uerj mesmo sendo um Instituto da Uerje é Educação Básica e pública e tem direito sim à merenda escolar gratuita para todos os estudantes. Ainda não foi possível a merenda escolar porque o atual espaço não comporta um refeitório para atender a todos os estudantes da escola básica. [...] Em 2015 o Estado autorizou a construção do refeitório, mas por causa do projeto que não era adequado e tinham problemas na dinâmica e depois falta de dinheiro o projeto não foi para frente [...] O Ministério Público havia informado que o Reitor até agosto/2018 tinha que tomar uma decisão (ex-representante - GRUPO APP, 2019).

Este depoimento indica como o desenho da demanda foi se constituindo desde 2015, em diálogo desde aquele momento com o Legislativo. Este relato embasou as ações dos atuais responsáveis a seguir com a demanda, devolvendo-a novamente para 
o Legislativo. Contudo, deixa a entrever o problema da provisoriedade do prédio, no esperado cumprimento da promessa de construção da cozinha, fator que justifica a não oferta de alimentação para os alunos.

A participação dos sujeitos da escola através do colegiado da APP e como contexto da prática coloca em relevo a possibilidade e a necessidade deste de localizar e identificar um problema que interfere na rotina e no desempenho dos estudantes. Além disso, busca-se também a mobilização de outros responsáveis da escola na expectativa, tanto de encontrar soluções que atendam aos problemas evidenciados, como também de adensar à demanda que pretendem encaminhar. Assim, os responsáveis, por meio da APP avançam na necessidade de resolução do problema:

a APP questionou que o refeitório poderia ser construído porque um prédio novo ainda pode demorar anos. E a prioridade tem que ser o estudante porque os direitos foram surrupiados por anos e é hora de dar um basta nessa situação (responsável representante - GRUPO APP, 2019).

Na leitura que fazemos sobre a política como um ciclo, o processo de contestação da política se constitui como efeito da relação entre o plano da orientação - contexto de influência - e o plano da ação - contexto da prática - e esta relação conduz a respostas inesperadas, mobilizadoras da ação dos sujeitos quando a política entra em cena, ou mesmo, como aqui é o caso, quando esta não chega à cena.

Ball et al (2016) defendem que não é exatamente o texto político que estabelecerá as ações da prática, já que a política é pensada para a escolha de melhores condições, geralmente construídas nas mentes dos seus formuladores em condições ideais. Partindo desse princípio, os agentes do contexto de influência, ao imaginarem a política de alimentação escolar, não previram outros caminhos para a atuação da política em estabelecimentos que não apresentassem condições físicas de preparo e acolhimento das refeições. A situação do CAp demonstra que o contexto da prática se configura como o espaço em que as políticas não são simplesmente implementadas, mas sobretudo, onde são encenadas e reinterpretadas pelos sujeitos. Elas se "tornam" políticas num processo centrípeto, quando saem do espaço em que foram idealizadas para serem colocadas em ação no contexto da prática e, centrífugo, quando dentro do contexto da prática a política é encenada pelos seus destinatários. Neste movimento, a política é "analisada e revista, bem como, por vezes, dispensada ou simplesmente esquecida" (BALL; MAGUIRE; BRAUN, 2016, p.15).

Como um exemplo dos diversos modos de fazer política quando esta é encenada, uma fala chama-nos atenção na análise dos dados deste estudo. Nela, há a sugestão do uso do hashtag para o começo de um movimento nas redes sociais, que tem como objetivo extrapolar o espaço da instância educacional, ampliando o grupo de sujeitos que adensem a demanda requerida pelo grupo. Logo, um dos integrantes da APP convoca 
o grupo para uma mobilização em outros ambientes virtuais: "outra coisa importante é colocar \#merendaescolarparacapuerj em cada postagem, em cada comentário" (responsável representante - GRUPO APP, 2019).

Seguindo as mobilizações no grupo, uma nova ação é colocada em cena sobre uma assembleia da APP realizada em 16 de março de 2019, nas dependências do CAp. Nessa reunião, os responsáveis decidem elaborar um texto para ser apresentado publicamente na Comissão de Educação da Alerj, em 20 de março de 2019, para requerer, dentre outros pontos, a oferta pela alimentação escolar. No texto lido pela representante da APP e, posteriormente, entregue ao presidente da Comissão de Educação da Alerj foram elencados cinco tópicos, sendo que a alimentação escolar assumiu o primeiro lugar na pauta das reivindicações. Destacamos, em seguida, o trecho no qual os responsáveis se referem à demanda pela alimentação:

1. Reafirmam a reivindicação e o justo direito à merenda escolar para todos os alunos da unidade escolar; 2. Registram de antemão que se contrapõem a qualquer possibilidade de que soluções parciais e provisórias se tornem permanentes. Consideram, no entanto, que são uma forma a curto prazo de viabilizar rapidamente o atendimento à necessidade e ao direito legal dos alunos de merenda escolar, mantendo no horizonte o atendimento global a toda a unidade escolar. 3. Pleiteiam a oferta de almoço para parte dos alunos, fazendo uso o quanto antes das instalações de pequeno porte de cozinha industrial e refeitório existentes na unidade, de acordo com a capacidade de atendimento possível hoje; 4.Reivindicam a construção de unidades modulares de cozinha industrial e refeitório que permitam a oferta de almoço e merenda fria aumentando a capacidade de atendimento[...] (carta do coletivo de responsáveis - GRUPO APP, 2019).

Segundo o relato do grupo após o encaminhamento da carta para a Alerj, a ação do contexto da prática parece ter mobilizado o Legislativo em duas questões: 1) pensar sobre a permanência da escola no atual prédio do CAp, pois esta decisão mantém relação com a construção de uma cozinha definitiva que possa oferecer alimentação adequada aos alunos e 2) a decisão, como ação emergencial, que a alimentação fria e parcial seria ofertada para os alunos.

Sobre os achados, é possível afirmar que o contexto escolar pode interferir numa política e na possibilidade de criar e modificar contextos a partir do que consideram as teorias da atuação política, pois as ações dos sujeitos colocadas em cena se relacionam com diferentes tipos e atores das políticas. À medida em que os membros da APP requerem a garantia da alimentação escolar, estes se constituem como sujeitos na cena da atuação da política, anunciando o aninhamento com os representantes do Legislativo. Neste movimento de articulação, conseguem a promessa de atendimento parcial de sua demanda, fator ainda não ideal para os estudantes, mas que indica, em alguma medida, uma resposta ao movimento realizado pela comunidade escolar e a possibilidade de prosseguimento da luta. 
Em uma perspectiva que considera a participação como elemento da democracia nas escolas é importante pontuar como a colegialidade, ação conjunta dos sujeitos, é capaz de movimentá-los para ação política. Assumimos que esta atuação é capaz de articular sujeitos numa determinada configuração de "tempo e de poder" (MOUFFE; ERREJÓN, 2016), buscando a garantia da objetivação de sua demanda. Decorre, deste cenário, que a comunidade permaneça acompanhando/reivindicando a demanda até o momento não atendida. Manter a articulação pela demanda, ampliando as experiências de participação na relação com o contexto de influência - o Legislativo do estado do RJ - trazendo ainda a gestão escolar para o debate. Este parece-nos, agora, o caminho que, possivelmente, irá conduzir ao asseguramento da alimentação escolar para os alunos do CAp.

\section{Considerações finais}

O movimento do colegiado da APP do CAP indica a presença de mobilização coletiva dos sujeitos na escola, bem como, mostra a possibilidade de institucionalização de espaços de participação democrática. Para nós, a escola é uma instituição que se faz no coletivo e o ambiente democrático enamora a oportunidade de institucionalização destas práticas participativas com o objetivo de ampliar a ação política na perspectiva de entender quem, na escola, pode e deve fazer política.

A política posta em cena através de seu texto tende a traduzir o projeto do contexto de influência para uma política educacional. Entretanto, como não há garantias para a materialidade de tal projeto, entendemos que a comunidade faz parte do conjunto de sujeitos do contexto da prática que faz movimentar a política, ou seja, pode requerê-la, considerando a especificidade de seu contexto de ação. É possível observar que, no caso analisado, o contexto da prática enuncia a não atuação da política e procura uma articulação legítima por meio de um ordenamento legal no encaminhamento de sua demanda com o contexto de influência.

Neste sentido, consideramos que a ação dos sujeitos na dinâmica da política configura-se como relações de poder capazes de, num determinado tempo, fazer valer uma demanda. Estamos diante de um quadro no qual há um compromisso do Legislativo na oferta de merenda fria, o que não ocorreu desde 2015, em demanda encaminhada pela ex-integrante da APP que esteve em contato como o Legislativo do estado, ou mesmo em 2016, durante o movimento de ocupação dos jovens.

Não é para menos reconhecer que o atendimento a uma demanda específica se constitui por um conjunto de ações que encontram as "brechas por onde entrar" (MOUFFE; ERREJÓN, 2016) e fazer tal demanda acontecer. Isto significa compreender também que as relações de poder ocupadas pelos sujeitos da política configuram-se como variantes nos contextos em que a política disputa significados. Posições que concorrem para 
legitimar um determinado projeto político que, na atual configuração da Casa Legislativa, parece estar favorável ao atendimento da demanda encaminhada pelos responsáveis da APP do CAp.

Recebido em: 14/10/2019 e Aprovado em: 25/11/2019

\section{Notas}

1 Movimento caracterizado pela tomada das escolas públicas pelos jovens, primeiramente com vistas a reafirmar as pautas da greve dos professores, iniciada em março de 2016, construindo, a partir desta adesão, demandas que diziam respeito às condições de alunos do estado. Neste contexto, as ocupações impulsionam a participação política dos secundaristas no debate sobre educação no estado (CASTRO; AMARAL, 2019).

\section{Referências}

BALL, Stephen; MAGUIRE, Meg; BRAUN, Anette. Como as escolas fazem as políticas: atuação em escolas secundárias. Tradução de Janete Bridon. Ponta Grossa: Editora UEPG, 2016.

BOWE, Richard; BALL, Stephen; GOLD, Anne. Reforming education \& changing schools: case studies in policy sociology. London: Routledge, 1992.

BRASIL. Decreto-lei no 9.053/1946. Cria um ginásio de aplicação nas Faculdades de Filosofia do País. Disponível em: https:/www2.camara.leg.br/legin/fed/declei/1940-1949/decreto-lei-9053-12-marco-1946417016-publicacaooriginal-1-pe.html. Acesso em 08 jun. 2019.

BRASIL. LDBN 9394/96. Lei de Diretrizes e Bases da Educação Nacional, v. 9394.

BRASIL. Lei n⿳0 11.947 de 16 de junho de 2009. Dispõe sobre o atendimento da alimentação escolar e do Programa Dinheiro Direto na Escola aos alunos da educação básica. Disponível em: < http://www. planalto.gov.br/ccivil_03/_ato2007-2010/2009/lei/111947.htm. Acesso em: 09 jun. 2019.

CASTRO, Marcela Moraes de; AMARAL, Daniela Patti do. Estudantes em cena: a ocupação como estratégia política pela gestão democrática no Rio de Janeiro. e-Mosaicos, v. 8, n. 17, p. 3-18, 2019.

COSTA, Celia. Deputado pedirá à Alerj para fazer bandejão no CAp-UERJ. Disponível em: https:// oglobo.globo.com/rio/deputado-pedira-alerj-para-fazer-bandejao-no-cap-uerj-19374662.Acesso em: 06 jun, 2019.

FUNDAÇÃO LEMANN. Disponível em: < https://www.qedu.org.br/escola/174863-instituto-deaplicacao-fernando-rodrigues-da-silveira-capitao-uerj/sobre> Acesso em: jun. 2019.

GOULART, Janaína Moreira de Oliveira; AMARAL, Daniela Patti do. Conselhos Escolares na Rede Estadual do Rio de Janeiro: participação ou participacionismo? Revista de Educação da UFSM.

Educação, v. 44, 2019.

Instituto de Aplicação Fernando Rodrigues da Silveira (CAp/UERJ), Projeto Político Pedagógico. Rio de Janeiro, RJ, 2013. Cap/UERJ, 2013. Disponível em: http://www.cap.uerj.br/site/images/stories/noticias/ projeto-politico-pedagogico-1.pdf 


\section{Legislações Consultadas}

LIMA, Licínio. A Escola como Organização e a Participação Escolar: um estudo da escola secundária em Portugal (1974-1988). Braga: Centro de Estudos em Educação e Psicologia/Instituto de Educação e Psicologia/Universidade do Minho, 1998.

LIMA, Licínio. A escola como organização educativa. 2a ed. São Paulo: Cortez, 2003. p. 69-92.

LIMA, Licínio. A gestão democrática das escolas: do autogoverno à ascensão de uma pós- democracia gestionária? Educ. Soc., v. 15, no129, p. 1067-1083, out.-dez. 2014.

MARTINS, Ângela Maria et al. Cenários de gestão de escolas municipais no Brasil: questionário contextual da Prova Brasil. Cadernos de Pesquisa, v. 48, n. 170, p. 1038-1061, 2018.

MOUFFE, Chantal. Entrevista. Bruno M. Lorenzetto Fernanda B. Gonçalves, José Arthur C. de Macedo, Miguel Gualano de Godoy. Chantal Mouffe - Entrevista. Revista da Faculdade de Direito UFPR, v. 51, p. 237-254, 2010.

MOUFFE, Chantal; ERREJÓN, Ígino. Construir pueblo. Hegemonía y radicalización de la democracia. 2ed. Barcelona: Icaria, Más Madera en profundidad, 2016.

O Dia. Estudantes reivindicam merenda gratuita e ocupam CAp-Uerj. Rio de Janeiro, 20/05/2016. Disponível em: https://odia.ig.com.br/_conteudo/rio-de-janeiro/2016-05-19/estudantes-reivindicammerenda-gratuita-e-ocupam-cap-uerj.html Acesso em: 06 jun. 2019.

OLIVEIRA, Ivana Campos; MENEZES, Iône Vasques. Revisão de literatura: o conceito de gestão escolar. Cadernos de Pesquisa, v. 48, n. 169, p. 876-900, 2018.

SILVA, Edleuza Oliveira; AMPARO-SANTOS, Lígia; SOARES, Micheli Dantas. Alimentação escolar e constituição de identidades dos escolares: da merenda para pobres ao direito à alimentação. Cadernos de Saúde Pública, v. 34, p. e00142617, 2018.

SOUZA, Ângelo Ricardo de. As condiçoẽs de democratização da gestão da escola pública brasileira. Ensaio: aval. pol. públ. Educ., Rio de Janeiro, p. 1-20, 2018.

VINHA, Terezinha Camargo Pompeo. Alimento na escola. LDB e seus desdobramentos. Revista Retratos da Escola, Brasília, v. 10, n. 19, p. 551-564, jul./dez. 2016. 